\title{
Reduction of the Climate Impact of Finnish Greenhouse Vegetables Achieved by Energy Acquisitions between 2004 and 2017
}

\author{
Frans Silvenius* and Juha-Matti Katajajuuri \\ Sustainability Science and Indicators, Natural Resources Institute Finland (Luke), Helsinki, Finland
}

\begin{abstract}
The scope of the study was the average climate impact of tomato, cucumber, and lettuce produced in heated greenhouses. The functional unit was one kilogramme of final product at the farm gate. Comparable data sets were used in the situation in 2004 and 2017. Main finding was that changes in energy profiles, especially increasing contribution of renewable energy instead of fossil ones, remarkably decreased climate impact of vegetables. The climate impact of greenhouse tomatoes has declined by $61 \%$ since 2004 . Respectively, the climate impact of greenhouse cucumber has declined by $49 \%$ and for lettuce by $35 \%$, since 2004 . There is, however, still possible to continue the development to renewable energy, which can be supported by the authorities by for example lowering energy taxes for renewable energy use.
\end{abstract}

Keywords

Carbon footprint, Greenhouse vegetables, Renewable energy, Tomatoes, Greenhouse, Finland

\section{Introduction}

According to previous studies, $19 \%$ of the climate impacts associated with consumption comes from food production and consumption in Finland [1]. In other western countries different results have been reported: Nijdam, et al. [2] is quite near, $23 \%$, but a review article of Tukker and Jansen [3] announce the share of food production varies between 3.6 and $31.0 \%$. Significant reductions in climate impact can be made through individual dietary choices [4-7] and a decrease in food waste and loss [8-10]. There is great potential to decrease the climate impact of particular food supply chains. Food production systems are developing continuously, which means that their climate impact is also often reduced.

The climate impact of greenhouse vegetable products depends e.g. on the season, the type of production system and technologies, the climatic production area, the amount of yield levels, and the energy production need and profiles [1116]. In the Mediterranean, vegetables production is largely based on soil-based production, unheated tunnel or greenhouse production. Previous studies show that this type of greenhouse production has a lower climate impact compared to more high-tech heated greenhouse production. There, the production of greenhouse structures, auxiliary equipment, and fertilisers are typically the main contributors to the climate impact of production [11,12,17], and for soil-based production location-specific variables such as climate and soil type are important [18].
In the heated greenhouse, such as in Finland, plants are grown in a sheltered environment seasonally or year-round. Main greenhouse vegetables grown in Finnish greenhouses are tomatoes, cucumbers and lettuce. Finns eat around $12 \mathrm{ki}-$ los of tomatoes per capita every year, $59 \%$ of that is domestic production. Correspondingly, Finns eat around 10 kilos of cucumbers per capita per year, with $88 \%$ domestic production rate [19]. Lettuce is eaten less. Finnish production is mainly lettuce in pots. $95 \%$ of lettuce in pots consumption is produced in Finland. The production in Finland is taken place in heated greenhouses. These use heating energy as well electricity for lighting and other automation. Lighting and heating is needed especially in year-round production, but also in seasonal production. Heating energy is most commonly produced in heating plants connected to greenhouses, using different fuels. Production and technology is being developed in different ways all the time, for example, LED lights are being

*Corresponding author: Frans Silvenius, Natural Resources Institute Finland (Luke), Sustainability Science and indicators, Helsinki, Finland

Accepted: March 25, 2021

Published online: March 27, 2021

Citation: Silvenius F, Katajajuuri JM (2021) Reduction of the Climate Impact of Finnish Greenhouse Vegetables Achieved by Energy Acquisitions between 2004 and 2017. J Hortic Sci Res 4(1):135-145 
used to replace high-pressure sodium (HPS) lights. This development also potentially decreases climate impact of vegetables production and products [20].

Horticultural production solutions and greenhouse infrastructure differ between cold and warm climates, and these have an essential effect on the climate impact of vegetable production and products. The main contribution of the climate impact of horticultural production is energy consumption for heating and lighting in northern countries (the Nordic countries and Central Europe) with a colder climate. Correspondingly, greenhouse production in southern countries with a warmer climate has lower energy requirements, where direct energy use for production is rarely required $[11,13,17]$.

In Central and Northern Europe and North America, climate impacts of vegetables produced in heated greenhouses are ranging from 1.6 to $10.1 \mathrm{kgCO}_{2}$-ekv/ $\mathrm{kg}[11,21-25]$. The results depend on whether seasonal cultivation or all-year cultivation was taken place, used energy sources, and even outside temperature. When renewable heat energy sources are used, the climate impact in Central and Northern European production can be even in the range of 0.3-0.7 $\mathrm{kgCO}_{2}$-ekv/ $\mathrm{kg}[14,16]$.

There is a clear potential to decrease the climate impact of heated greenhouse production. Energy use has been known to have positive association to carbon emissions [26] and on the other hand renewable energy consumption is known to have the negative impact of environmental degradation in higher-income and upper-middle-income countries [27]. It means that way to reduce emissions is to change energy source, but it is also possible to reduce energy consumption by developing production $[16,28]$. Finnish previous investigations, like Kaukoranta, et al. [29] show how it is possible to reduce the energy consumption of greenhouse production. For example a semi-closed greenhouse in summer improved energy efficiency by $20-30 \%$ and split-roof fertigation by $0-15 \%$. In addition a higher light intensity in winter provided a higher yield without impacting the efficiency of electricity use.

The background for the study was that we knew according to Yrjänäinen, et al. [30] and Silvenius [16] as well as according to Torrellas, et al. [28] and Ntinas, et al. [14] that greenhouse production can reduce its climate impact remarkably by changing to use more renewable energy, instead of fossil ones. So our research question is that how much the sector as whole has so far done energy source change: What is the average energy profile today for the greenhouse sector and how much the climate impact has decreased since year 2004, due to the energy source changes and other development in greenhouse sector.

This article includes the results of an investigation of the climate impact of Finnish greenhouse vegetables production. We focus on Finnish greenhouse production, because there has thus so far been no scientific research about the average climate impact of Finnish greenhouse production or its changes.

We compare the average climate impact of tomato, cucumber, and lettuce produced in Finnish heated greenhous- es, as well as the climate impact of the entire greenhouse sector in 2004 and 2017, based on a life-cycle approach focusing on climate impact (carbon footprint). Carbon footprint assessment is increasingly recognised for assessing the climate impacts of food products by quantifying all the greenhouse gas emissions caused by a particular food production chain, here for vegetables production chain. It should be kept in mind that climate impact alone should not be considered an indicator of environmental sustainability and it only one part of actual life cycle assessment.

\section{Materials and Methods}

\section{Functional unit and system boundaries}

The functional unit was one kilogramme of final product at the farmgate, based on the average production of tomatoes, cucumber, and lettuce in 2004 and 2017. The system boundaries followed much the horticulture climate impact standard [31], so they include nurseries, fertiliser and lime production and use, substrate production, packaging and pot production, carbon dioxide use for enrichment in greenhouses and related production, the irrigation, lighting, and heating of greenhouses, electricity and heat energy production, compostable plant waste production and end-of-life, substrates, and packaging. Logistics, the consumer element, and trade were not included in the study. Nor were construction and maintenance of greenhouse infrastructure, as recommended in PAS 2050-1:2012 [31]. Logistics were excluded from the system boundaries, so in that part PAS 2050-1:2012 was no followed and it was thought that there had not been remarkable changes in logistics between production years.

\section{Data collection and sources}

Energy: The reason of the study was to investigate the changes of climate impact of Finnish greenhouse vegetables during 2004 and 2017. Amounts of energy, production volumes, and energy profiles were based on the actual horticultural statistics of Luke [32] of the corresponding years (Table 1), because they describe well the typical greenhouse production of Finland as whole. For other components, the inputs and outputs relating to the area were assumed to be the same since they have rather limited contribution to the results (Table 2 ).

Studies in 2004 and 2017 were undertaken using the same scope and assumptions, so that the farms in the investigation were chosen deliberately to include only those producing cucumber, tomatoes, or pot vegetables to avoid allocation problems and to attain a high comparability of results between different production years. For lettuce, some of the farms also produced other pot vegetables, and the allocation between crops was based on the cultivated area. However, the amount of pot vegetables was very low compared to the amount of lettuce produced. There were some differences between production in 2004 and 2017, and e.g. special tomatoes, which are mainly cherry tomatoes, were produced in 2017 but not in 2004. Because cherry tomatoes have a larger energy requirement per kilo of product due to the smaller yield, the results are also presented per average of total tomatoes and as an average without cherry tomatoes. 
Citation: Silvenius F, Katajajuuri JM (2021) Reduction of the Climate Impact of Finnish Greenhouse Vegetables Achieved by Energy Acquisitions between 2004 and 2017. J Hortic Sci Res 4(1):135-145

Table 1: The number of farms in the climate impact assessment and the share of the total production volume, cultivation seasons, areas, and average yields of the farm data used in climate impact assessment.

\begin{tabular}{|l|l|l|l|l|l|l|}
\hline & \multicolumn{3}{|l|}{ Cucumber } & \multicolumn{2}{l|}{ Lettuce } \\
\hline & $\mathbf{2 0 0 4}$ & $\mathbf{2 0 1 7}$ & $\mathbf{2 0 0 4}$ & $\mathbf{2 0 1 7}$ & $\mathbf{2 0 0 4}$ & $\mathbf{2 0 1 7}$ \\
\hline Number of farms & 232 & 99 & 107 & 35 & 15 & 17 \\
\hline Average area of farms, $\mathrm{m}^{2}$ & 2,941 & 5,157 & 2,991 & 5,769 & 6,933 & 6,731 \\
\hline Average yield, $\mathrm{kg} / \mathrm{m}^{2}$ & 33 & 44 & 44 & 103 & 50 & 50 \\
\hline Number of year-round farms & 56 & 44 & 63 & 54 & 81 & 96 \\
\hline $\begin{array}{l}\text { Share of production volume of studied farms } \\
\text { of total Finnish production, } \%\end{array}$ & 58 & 67 & 46 & 48 & 74 & 85 \\
\hline
\end{tabular}

Table 2: Inputs of finish greenhouse production in 2004 and 2017.

\begin{tabular}{|c|c|c|c|c|c|c|}
\hline & \multicolumn{2}{|c|}{ Tomato } & \multicolumn{2}{|c|}{ Cucumber } & \multicolumn{2}{|c|}{ Lettuce } \\
\hline & 2004 & 2017 & 2004 & 2017 & 2004 & 2017 \\
\hline Heat energy, $\mathrm{kWh} / \mathrm{kg}$ & 13.24 & 9.84 & 7.52 & 2.73 & 6.72 & 13 \\
\hline Electricity, kWh/kg & 2.89 & 3.32 & 3.91 & 7.64 & 9.90 & 13.89 \\
\hline Peat, $\mathrm{m}^{3} / \mathrm{t}$ & 0.117 & 0.088 & 0.093 & 0.040 & 0.21 & 0.21 \\
\hline Mineral wool, kg/t & 13.3 & 10 & 10.84 & 4.63 & 23 & 23 \\
\hline Nitrogen fertiliser, $\mathrm{g} / \mathrm{kg}$ & 11.1 & 8.3 & 11.0 & 4.7 & 1.9 & 1.9 \\
\hline Phosphorus fertiliser, $\mathrm{g} / \mathrm{kg}$ & 2.1 & 1.6 & 1.92 & 0.82 & 0,65 & 0.65 \\
\hline Potassium fertiliser, $\mathrm{g} / \mathrm{kg}$ & 16.4 & 12.3 & 14.3 & 6.1 & 4.2 & 4.2 \\
\hline Carbon dioxide, $\mathrm{m}^{3} / \mathrm{t}$ & 1.5 & 1.1 & 1.19 & 0.51 & 0.4 & 0.4 \\
\hline
\end{tabular}

The number of greenhouse farms used in this climate impact assessment is presented in Table 1 , as well as the average cultivated areas, yield, share of year-round cultivation, and the study's representativeness in terms of the share of the total production volume. The share of seasonal cultivation in the studied farms in 2017 was larger than in 2004 for tomato and cucumber. According to the statistics, there was more year-round production in 2017 than in 2004 in terms of total greenhouse production, which differs from the data of the farms assessed in this study. For lettuce, almost the entire production was from the 2017 12-month period (Table 1). The representativeness of the production included in the investigation in relation to the total production of Finland is quite high, ranging from $46 \%$ to $85 \%$ (Table 1 ). There are smaller numbers of farms in 2017 than in 2004, but the average size of the farms has increased so that the actual representativeness is better in 2017 than in 2004.

Luke's statistical data (Energy consumption in greenhouse enterprises, Luke 2019 [32]), which include on farm level energy use, energy profiles, yields, and cultivation areas for Finnish greenhouse production were used as a source for yields, area, and consumed energy and heat energy profiles. In this investigation peat, which is known to be between fossil and renewable energy source, is treated as non-renewable energy meaning that in combustion process all the carbon content of peat evaporates as fossil carbon dioxide.

The emission factors for different heat energy categories were obtained from Alakangas, et al. [33], which is used e.g. in national greenhouse gas inventories, and the supply chain of the production of the used fuels was taken into account in the assessment, mainly based on Ecoinvent data. The average Finnish electricity profile was mainly used for the electricity profiles in 2004 and 2017. Some large producers were also using green electricity in 2017, and in these cases, we used an estimate of the average green electricity profile in Finland, based on Yrjänäinen [34]. The share of green electricity for cucumber was $14 \%$, for lettuce $31 \%$, and for tomatoes $26 \%$. Indeed, more producers as a whole were using green electricity in 2017, but their emissions were assumed to be the Finnish average because the official data on green electricity use on those farms did not exist. Electricity emissions from different energy sources were based on Ecoinvent, and the mixes were formed based on Finnish statistics. Infrastructure was included in the electricity production emission sources.

Fertilizers: For fertiliser use, the estimates of the experts of Finnish Glasshouse Growers' Association were used for 2017, because there were no statistics available concerning that. The same number of fertilisers in relation to cultivated area was assumed to be used also for 2004. The emission factors for $\mathrm{N}$ fertilisers for 2017 were based on the guarantee value of Yara Ltd, which means that climate impact does not exceed $3.6 \mathrm{kgCO}_{2}$-eq/ $\mathrm{kgN}$ [35]. The value is used, because Yara's fertilisers are widely used in Finland (market share more than $80 \%$ ) and thus used in climate impact investigations as well. The same data was also used for 2004, even though the guarantee value did not then exist. Ecoinvent data was used for $\mathrm{K}$ and $\mathrm{P}$ fertilisers. The nitrous oxide emissions of the fertiliser application and carbon dioxide emissions from lime application were calculated based on instructions for field cultivation by IPCC [36]. 
Carbon dioxide: The amount of industrial carbon dioxide used as enrichment for photosynthesis cultivation was divided into cultivated plants by modelling. The total amount of industry-based carbon dioxide used in greenhouses was received from the main producer of Finland [37] and allocated to the different plants with the simulation model, which considers photosynthesis functions, leaf areas, lighting, ventilation, heating, moisture, and $\mathrm{CO}_{2}$ control. The share of industrial carbon dioxide according with expert opinions was 52\%; the remaining $\mathrm{CO}_{2}$ enrichment came from farms' own heat energy production. For nurseries, the production profiles of Yrjänäinen, et al. [30] were used. For substrates, the amounts for each substrate were based on the expert opinions of the Finnish Glasshouse Growers' Association, because there were not available statistics for that. The amount of mineral wool was assumed to be $70 \%$ and peat $30 \%$, of the total volume. The number of other substrate uses was unremarkable, based on the estimates of the Finnish Glasshouse Growers' Association. The peat was modelled by considering the peat harvesting, degradation, and greenhouse balance of swamps. The carbon footprint of mineral wool was assessed based on Kool \& Blonk [38], and for peat on Seppälä, et al. [39], Silvan, et al. [40], Kirkinen, et al. [41], Kirkinen, et al. [42], and Pohjala 2014 [43].

Packaging: The amount of consumer plastic packaging was obtained from the investigation of the Finnish Glasshouse Growers' Association [44]. End-of-life was investigated so that the credits were calculated by using the energy yields and efficiencies of Vantaa Energia's waste and co-combustion plant. The replaced heat energy was assumed to be half natural gas and half coal energy, because this corresponds to the typical heat energy profiles in Helsinki and the surrounding area. The emission factors for natural gas and coal-based heat energy were from Alakangas 2016 [33]. The replacement electric energy was assumed to be average Finnish electricity.
Waste: The amount of plant-based waste, as well as their nitrogen and carbon content, was modelled in the previous project [30], and they were also assumed to be the same in this investigation. In composting, it was assumed that $50 \%$ of nitrogen evaporated and 1\% [45] of which was nitrous oxide. For carbon, based on the EASEWASTE model, 65\% evaporated and $3 \%$ of which was methane [46].

Waste: The transport of input production like substrates, carbon dioxide, and fertilisers was calculated based on the LIPASTO database [47], which offers a good description of the Finnish transport emission profile. Distances between farms and input production plants were calculated based on typical locations. The climate impact of consumer and secondary packaging were also included. PE film was used for cucumber packaging. Tomatoes were packed for retail in a consumer plastic bag or biodegradable bag, and they were not included, because the system boundaries ended up at the farmgate. Instead, corrugated board boxes used as transport packaging were included for all products. For lettuce, the polypropylene pots and plastic bags were included, because they are part of farm material use.

In characterisation, Factors 25 for methane and 298 for dinitrogen monoxide were used [48], because they are also used in the Finnish Greenhouse Gas Inventory.

\section{Results and Discussion}

\section{Results}

The inventory table of material and energy inputs in relation to one kg final products are presented in Table 2. There was no separate data collection for substrates, fertilisers, and carbon dioxide in 2004, so they were assumed to be the same in relation to one cultivated square metre for 2004 and 2017. The yield was better in 2017 than in 2004 for cucumber and

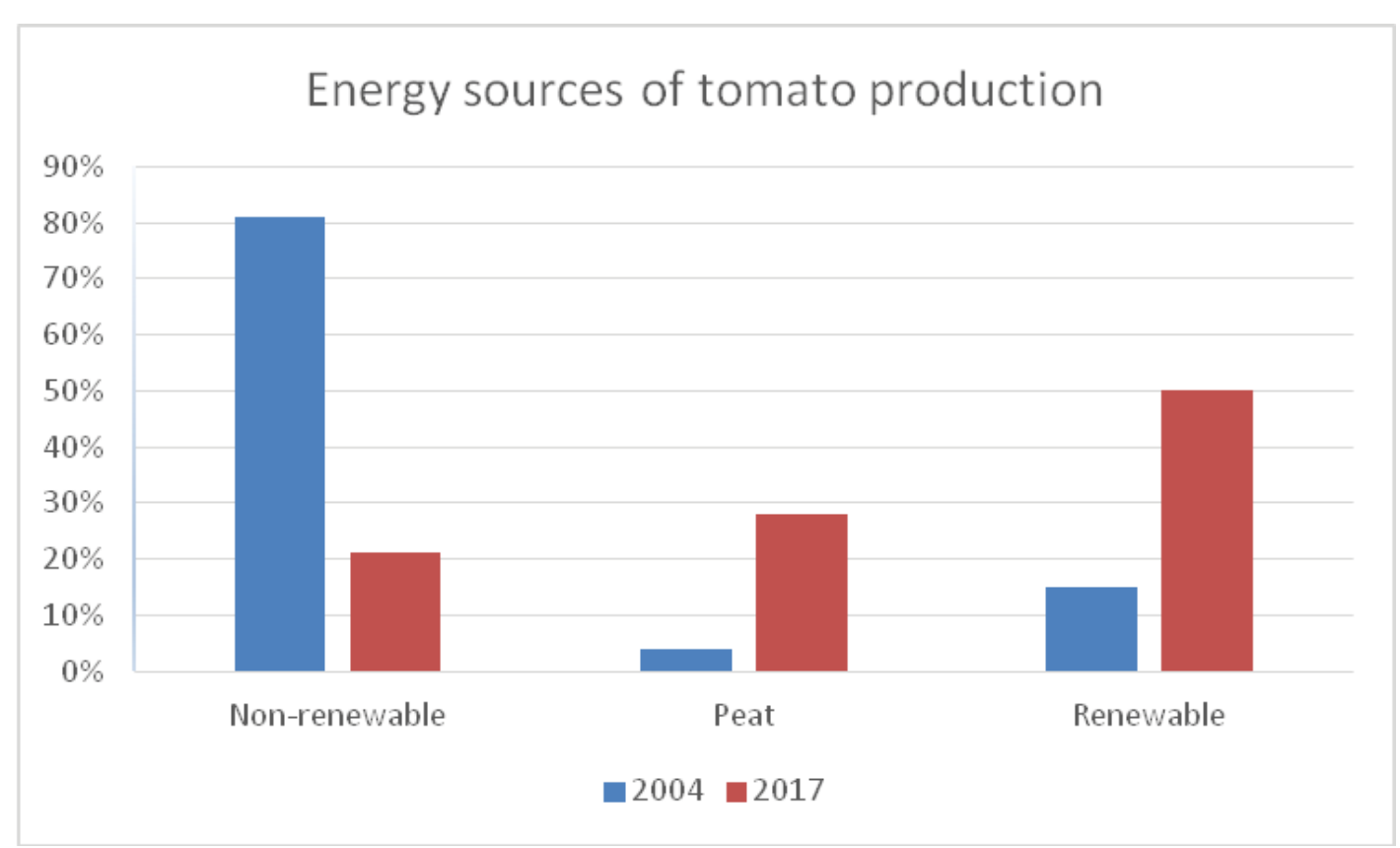

Figure 1: Share of the different energy sources tomato production in the investigated greenhouses in 2004 and 2017. 
tomato, and the amount of substrates, fertilisers, and carbon dioxide was higher in relation to one kg cucumber and tomato in 2004 than in 2017 (Table 2).

There has been a clear trend in production towards renewable energy: The share of renewable energy, mainly wood- and field-based, energy, like woodchips, wood pellets and straw in tomato and cucumber production has doubled, and in lettuce production it was seven times higher in 2017 than 2004. The renewable energy is mainly wood- and fieldbased energy, like woodchips, wood pellets and straw. However, the share of peat has increased in tomato cultivation by
$50 \%$. In cucumber production, it is three times higher, and in lettuce production 16 times higher in 2017 than 2004 (Figure 1 , Figure 2 and Figure 3). The share of non-renewable energy was $42 \%$ for cucumber and $21 \%$ tomato, only half that in 2004 for cucumber and about one third for tomato. The share of non-renewable energy for lettuce was 10\% in 2017 and 90\% in 2004.

The carbon footprint results for tomato include three calculations: The average for tomatoes in 2004 and 2017 and for tomatoes in 2017 excluding special tomatoes like cherry tomatoes. This was done to ensure comparability: Produc-

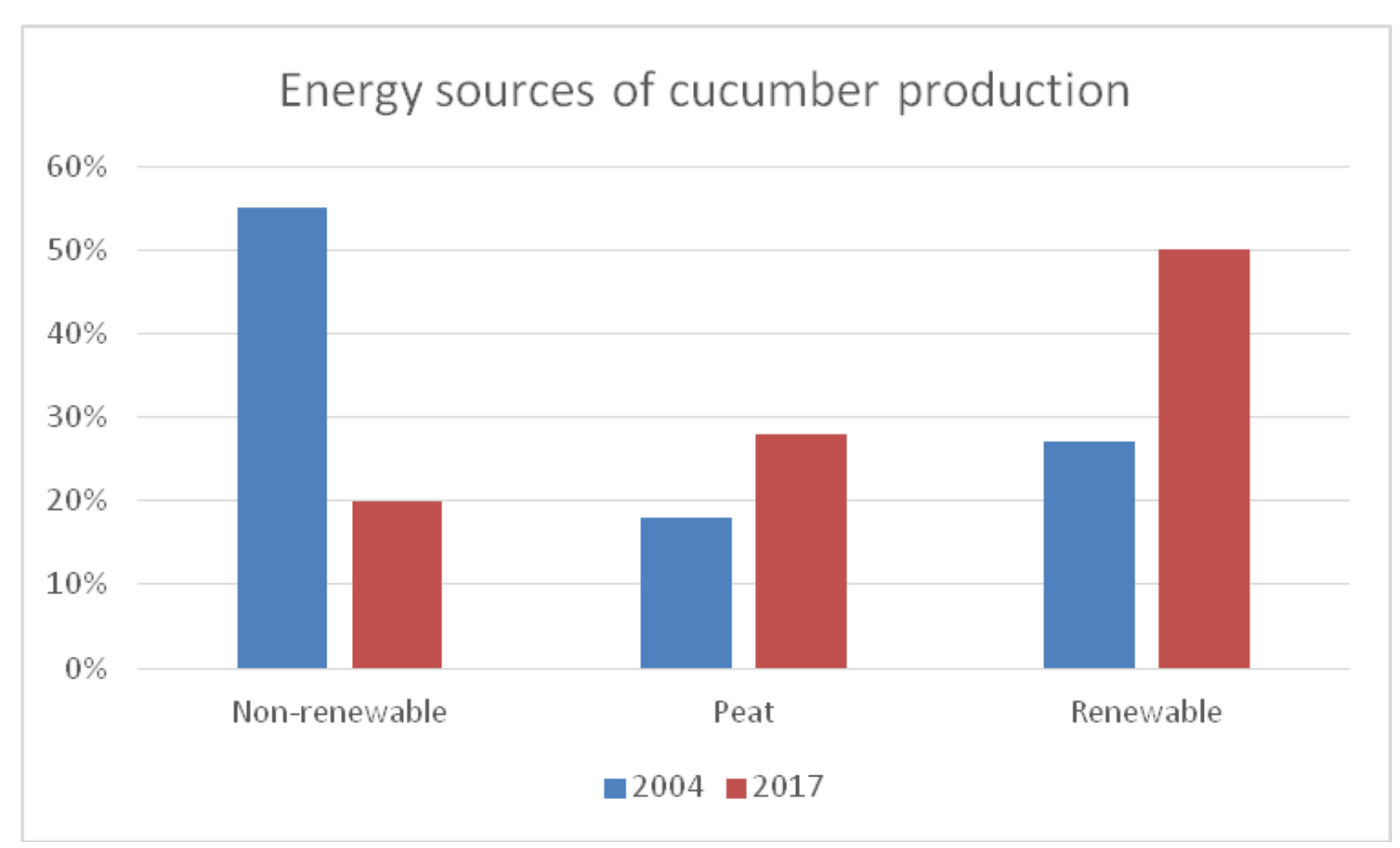

Figure 2: Share of the different energy sources cucumber production in the investigated greenhouses in 2004 and 2017.

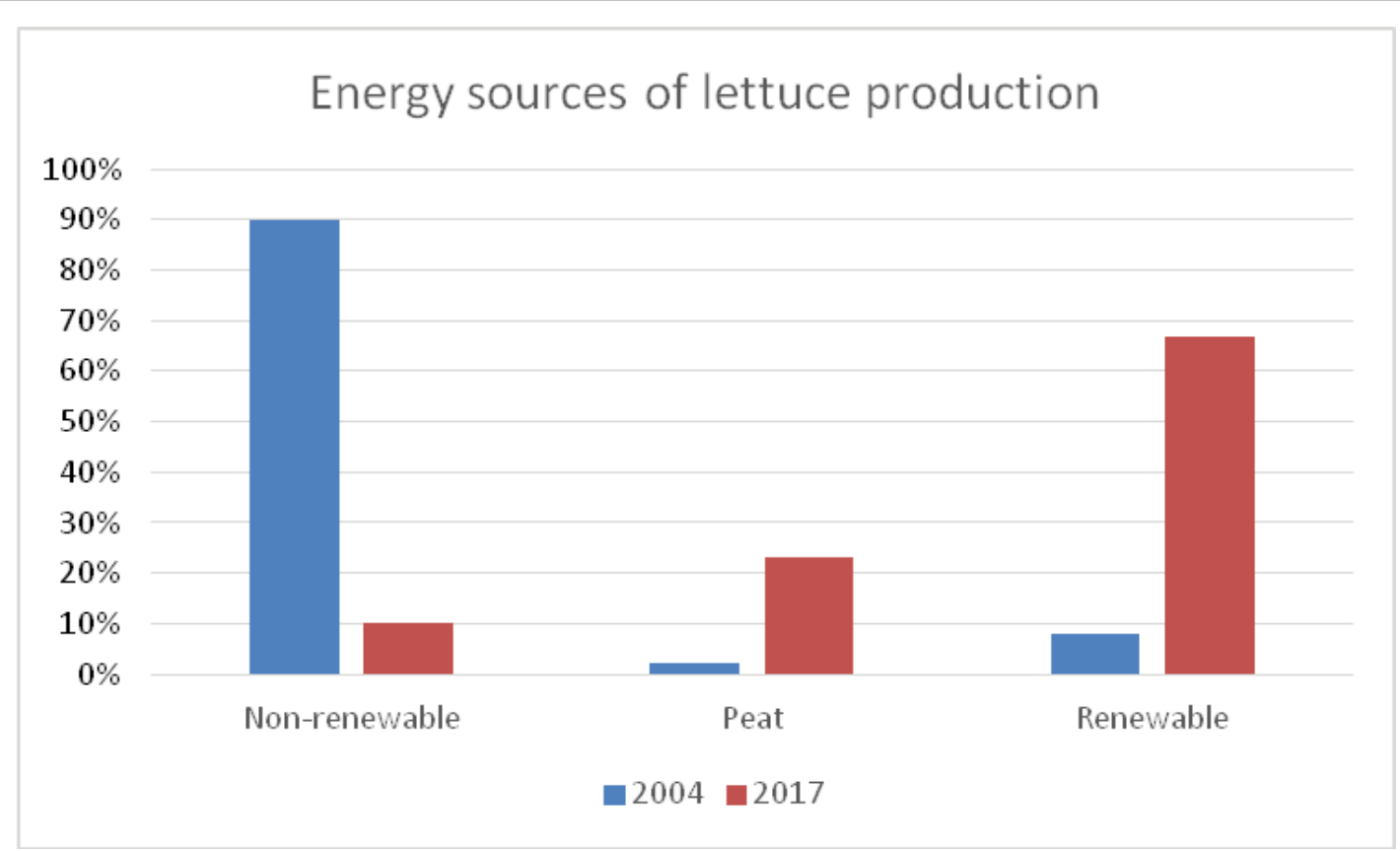

Figure 3: Share of the different energy sources cucumber production in the investigated greenhouses in 2004 and 2017. 


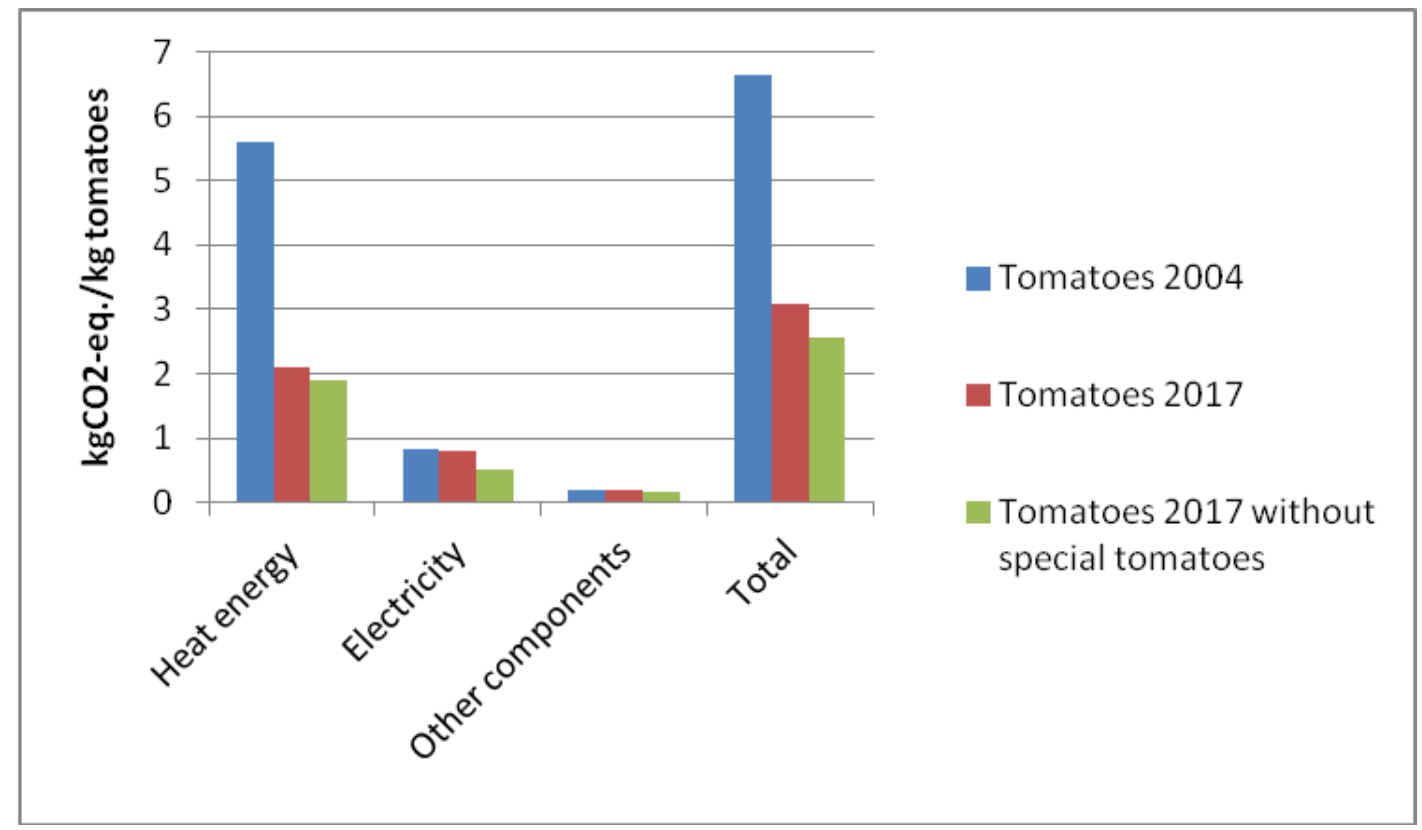

Figure 4: Climate impact of Finnish tomatoes in 2004 and 2017.

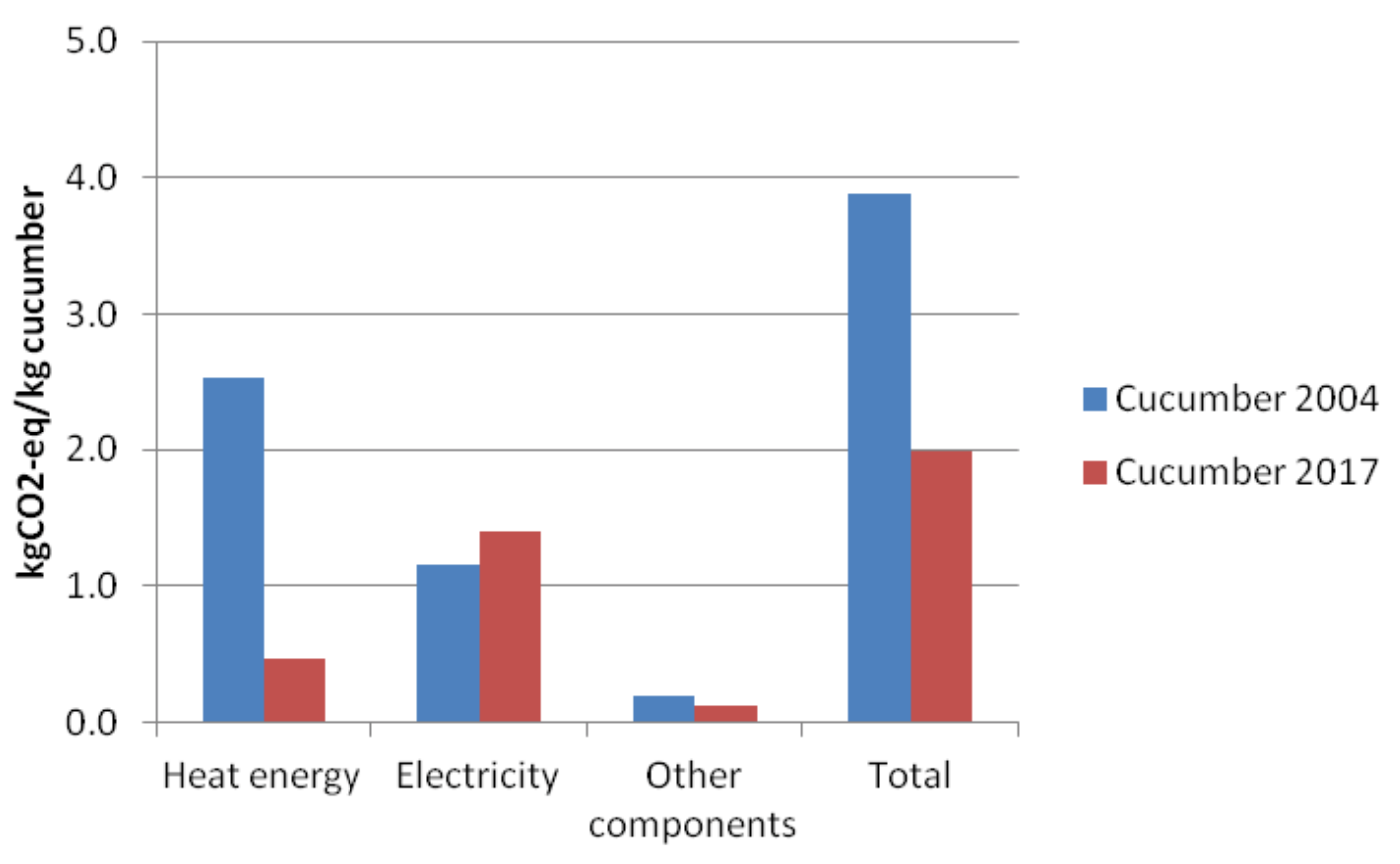

Figure 5: Climate impact of Finnish cucumber in 2004 and 2017.

tion in 2004 was mainly of conventional tomatoes. In relation to 2004 , the climate impact for conventional tomatoes decreased by $61 \%$ : Electricity by $38 \%$ and heat energy by $66 \%$ (Figure 4). The figures were $2.6 \mathrm{kgCO}_{2}$-eq/ $\mathrm{kg}$ for conventional tomatoes in 2017, $3.1 \mathrm{~kg} \mathrm{CO}$-eq/ $/ \mathrm{kg}$ for average tomatoes in 2017 , and $6.6 \mathrm{~kg} \mathrm{CO}-\mathrm{eq} / \mathrm{kg}$ for average tomatoes in 2004 . For conventional tomatoes, the contribution of heat energy was $74 \%$, electricity $20 \%$, and other components $6 \%$.

The reasons for the decreasing emission were increased yield, and changes in heat energy and electricity profiles. The heat energy use in relation to yield decreased by $26 \%$. The share of green electricity was $26 \%$, but this does not cover all the green electricity use in Finnish tomato production.

For cucumber, the climate impact was $2.0 \mathrm{kgCO}_{2}-\mathrm{eq} / \mathrm{kg}$ in 2017 and $3.9 \mathrm{kgCO}_{2}$-eq/ $\mathrm{kg}$ in 2004, and in 2017, the contribution of heat energy was $24 \%$, electricity $71 \%$, and other components $5 \%$. The total reduction of the climate impact was $49 \%$. The share of heat energy was reduced by $81 \%$, and the share of electricity increased by $22 \%$ (Figure 5 ).

One of the main reasons for the result was that the average yield increased between 2004 and 2017. This meant the amount of heat energy was lower in 2017 in relation to the 


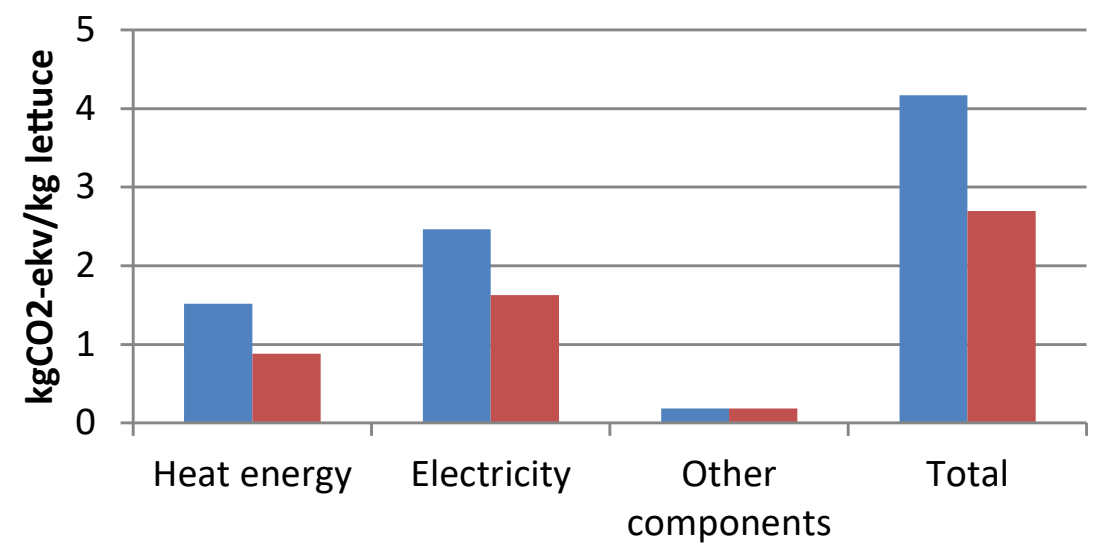

- Lettuce 2004

Lettuce 2017

Figure 6: Climate impact of Finnish lettuce in 2004 and 2017.

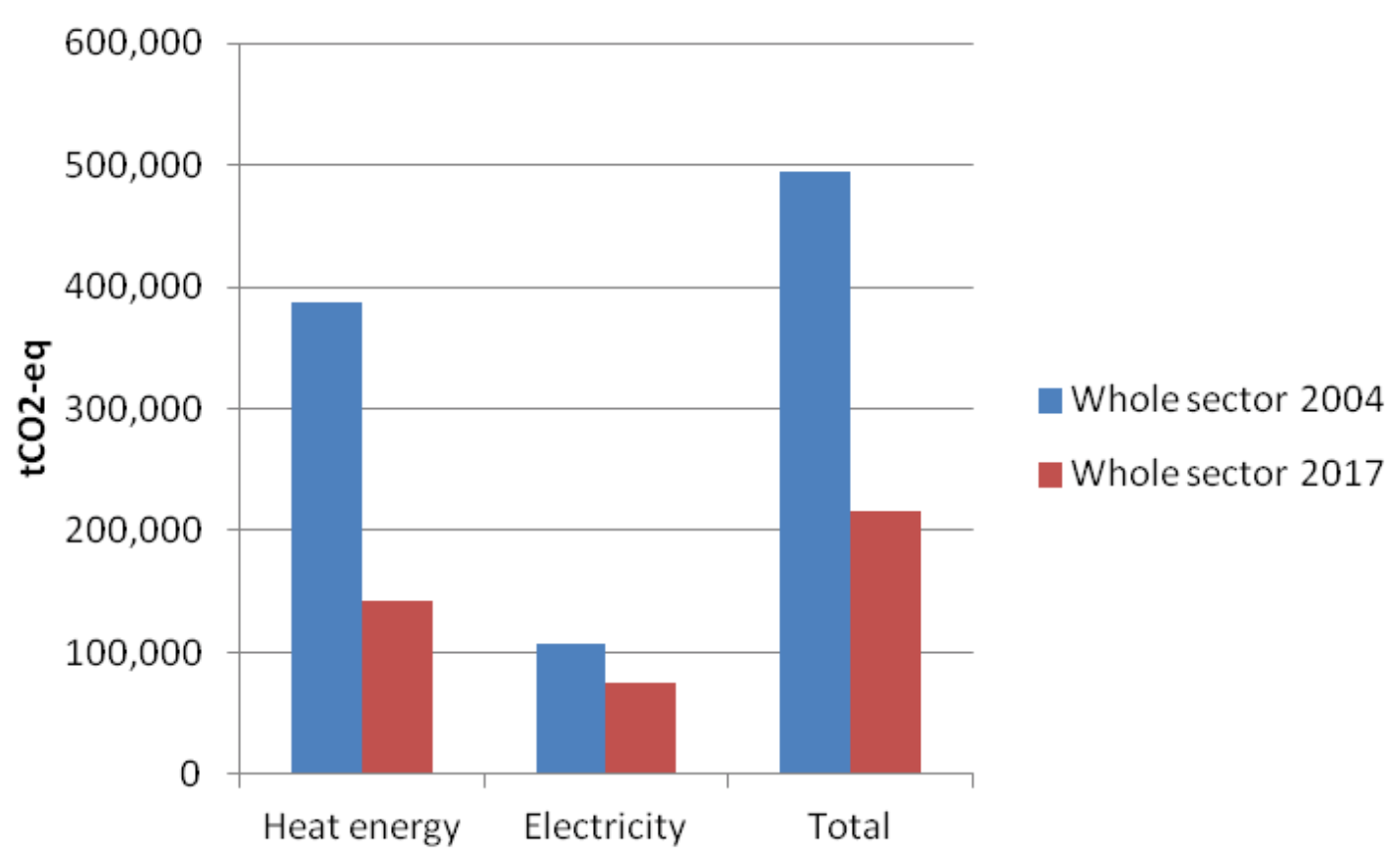

Figure 7: Climate impact of used energy in the greenhouse sector in 2004 and 2017.

produced amount of cucumber than in 2004. The heat energy profile also changed. On the other hand, electricity consumption in relation to cultivated area was four times higher in 2017 than in 2004. The amount of green electricity used in this calculation was $14.2 \%$ of the total electricity consumption, but this does not cover all the green electricity used in Finnish cucumber production. In addition, it must be kept in mind that the yield was two times more in 2017 than in 2004 and the greenhouse gas emission factors of 2017 are lower than these factors in 2004.

The climate impact of lettuce produced in Finnish greenhouses was $2.7 \mathrm{kgCO}_{2}$-eq $/ \mathrm{kg}$ in 2017, and $4.2 \mathrm{kgCO}_{2}$-eq $/ \mathrm{kg}$ in 2004 (Figure 6), the share of heat energy 33\%, electricity $60 \%$, and others $6 \%$. The climate impact decreased by $35 \%$, heat energy $42 \%$ and electricity $32 \%$. It is noteworthy that the share of electricity for lettuce is much higher than for cucumber and tomato. The contribution of renewable heat energy increased from $8.5 \%$ to $61 \%$, and fossil energy from $90 \%$ to $12 \%$, but the contribution of peat increased from $1.5 \%$ to $27 \%$. The increase in peat consumption as heat energy source explains why the heat energy decreased by only $42 \%$, although the share of renewable heat energy increased remarkably.

To produce the entire greenhouse sector energy use, the climate impact decreased by 56\% between 2004 and 2017. The share of heat energy decreased by $63 \%$, and electricity by $30 \%$ (Figure 7 ). However, much potential remains to reduce the climate impact of the greenhouse sector. If all the electricity used were green, it would reduce the climate impact of electricity consumption by $89 \%$, and if all the remaining fossil energy including peat were converted to renewable energy, the climate impact of heat energy would decrease by $81 \%$ (Figure 8). With both these changes, the reduction would be $84 \%$ of the climate impact of the entire sector. 


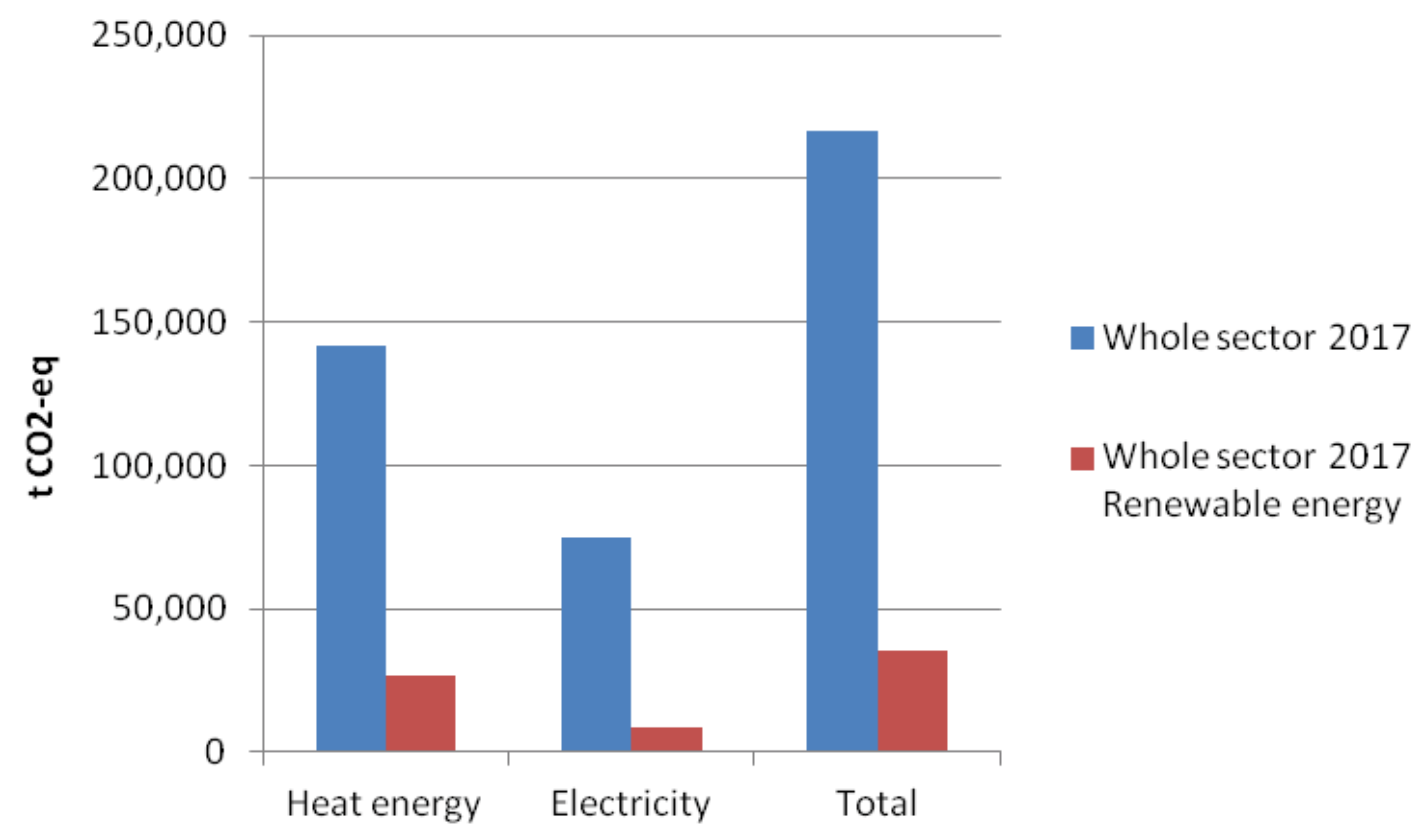

Figure 8: Climate impact of used energy in the greenhouse sector in present and future scenarios if all energy sources are renewable.

\section{Discussion}

This investigation focused on the evident climate impact hot spots of Finnish greenhouse production; because they were previously known to be heat energy and electricity use [30]. The use of other components, such as substrate amount, carbon dioxide enrichment, packaging, fertilisers, and transport were not included in the statistics, so this information was based on expert opinions by Finnish Glasshouse Growers' Association. This approach based on expert opinions with its related possible uncertainties had no significant impact on results, because the most reliable and important part of the results, contribution of heat and electric energy was 94$95 \%$. Contribution of other components of climate impacts was around $6 \%$. In previous climate impact investigations of heated greenhouse production, it has been observed also that the most important factors for climate impact are heat energy and electricity consumption for lighting as well as in this study. Henricks [49] has resulted the share of heat energy $80 \%$, Almeida, et al. [24] 63-75\% Theurl, et al. [23] 63\% and Dias, et al. [25], 69\%.

Interestingly, this investigation produced almost the same results for climate impacts for other parts of the life-cycle as energy stated in Yrjänäinen, et al. [30] and also results of the average energy use were on the same level. Climate impacts of Finnish vegetables were 2017, however lower, compared to the previous Finnish studies Yrjänäinen, et al. [30], which is based on a small sample of greenhouses and Katajajuuri, et al. [50], which was based on real statistical energy use of many greenhouses. In experimental research Kaukoranta, et al. 2014 [20] resulted 2.2-3.0 $\mathrm{kgCO}_{2}$-eq/ $\mathrm{kg}$ cucumber, but these are theoretical values and based on only one experiment which was not representative of average Finnish production.
In relation to the previous studies in other countries, it can be concluded that in general climate impacts of Finnish vegetables still in the 2017 situation are remarkably higher than in Southern Europe, North Africa, and the Middle East, where the climate impact of tomatoes and cucumber has been reported to be relatively low, varying between 0.06 and $0.6 \mathrm{~kg} \mathrm{CO}$-eq/ $/ \mathrm{kg}$ of product $[14,15,17,51-56]$. In Central and Northern Europe and North America, corresponding results has been obtained in relation to this study. In heated greenhouse vegetables, the most recent climate impact results has been from 1.37-3.59 kgCO - -ekv/kg [24], 1.4 kgCO - -ekv/kg [23] and, $3.2 \mathrm{kgCO}_{2}$-ekv/ $\mathrm{kg}$ [25], so the results are on the same level as in this study. The results depend on used energy sources, climate circumstances, yield and mainly whether seasonal cultivation or all-year cultivation was taken place in studies.

This investigation proves that there has been considerable improvement in greenhouse production in Finland between 2004 and 2017. The heat energy profiles have developed in a more climate-friendly direction. Fossil energy has been replaced by renewable, mainly wood- and field-based, energy, like woodchips, wood pellets and straw. The climate impact of conventional tomatoes declined by $61 \%$, of cucumber by $49 \%$, and of lettuce by $35 \%$. There have also been changes in electricity profiles: The average climate impact in relation to the produced amount of electricity was lower in 2017 than in 2004. Furthermore, in 2017, more farms were using green electricity with no direct greenhouse gas emissions. The share of green electricity for cucumber was $14 \%$, for lettuce $31 \%$, and for tomatoes $26 \%$. This is another reason that the results are so much lower in 2017 than in 2004. In addition, yield was $25 \%$ higher for tomato and even double for cucumber in 2017 than in 2004. The results for cucumber in 2004 were at the same level as presented by Katajajuuri, et al. 2007 [50]. These results are in line with previous findings: The share of heat 
energy has been 63-80\% Henricks 2012 [24], Almeida, et al. 2014 [49]. Theurl, et al. 2014 [23] and Dias, et al. 2017 [25], $69 \%$ and it is clear that changes in the heat energy profile in these cases would have the same impact to climate impact as in these studies.

A detail known to differ in the actual situation was the share of fertilisers: for both years, the Yara guarantee value was used, but in 2004, the fertilisers were produced using older technology without an uptake of the dinitrogen monoxide. However, the contribution of nitrogen-based fertilisers was only $1 \%$ of the total climate impact, so this has no significant impact on the final results. Technologies have also developed in greenhouse production.

Concerning uncertainties, a factor that may have affected the results was that year-round production in our data was overrepresented in 2004 for tomato and cucumber. Yearround production has a higher impact, so it is possible that the real change was not as remarkable as previously presented. Yet the total climate impact of the entire Finnish greenhouse sector according to this study was $56 \%$ less in 2017 than in 2004, which is in line with the results of this study.

One efficient opportunity to further reduce the carbon footprint is to reduce the use of peat in heat energy production: The contribution of peat to the climate impact for tomato was $38 \%$, cucumber $7.2 \%$, and lettuce $16 \%$. Based on our additional assessments if the entire electricity use were green electricity, the climate impact of electricity consumption would decrease by $89 \%$ and converting all the remaining fossil energy including peat to renewable energy would decrease the climate impact of heat energy by $81 \%$. With both these changes, the reduction would be $84 \%$ for the entire sector's climate impact.

These changes and the improvement potential support the regular repetition of such investigations to avoid the results becoming outdated. One of the main conclusions was that using old references in LCA investigations may lead to very misleading results, and data that is too old should not be used. Furthermore, when the comprehensive environmental sustainability impacts of greenhouse products are assessed, it is important to include other environmental impact categories such as the water footprint and eutrophication.

Our study clearly demonstrates the potential to decrease the climate impact of energy use in horticulture production. An interesting study was made by Dias [25], in which different climate impact studies were located in the same coordinates with the average annual temperature of the area. When the existing data is compared with the situation in Ontario, Cana$\mathrm{da}$, it can be seen that in the Finnish situation, a slightly lower climate impact can be achieved with a lower annual temperature. The energy used in relation to produced tomatoes is almost the same. The result is therefore caused by a difference in the energy profile: In the Canadian case, most of the climate impact came from natural gas and heavy fuel oil, but in Finland, their share is minimal. This leads to the final conclusion: Even in northern countries, a low climate impact can be achieved in greenhouse production if the production is based on renewable energy. There is also potential in addition to convert to renewable energy also to increase energy efficiencies in greenhouse production by using different technological solutions like the optimisation of lighting technology.

\section{Conclusion}

This investigation focused on the evident climate impact hot spots of Finnish greenhouse production, which were known to be heat energy and electricity use. This investigation proves that there has been considerable improvement in greenhouse production in Finland between 2004 and 2017. The heat energy profiles have developed in a more climate-friendly direction. Fossil energy has been replaced by renewable, mainly wood- and field-based, energy, like woodchips, wood pellets and straw. The climate impact of conventional tomatoes declined by $61 \%$, of cucumber by $49 \%$, and of lettuce by $35 \%$.

Based on our additional assessments if the entire electricity use were green electricity, the climate impact of electricity consumption would decrease by $89 \%$ and converting all the remaining fossil energy including peat to renewable energy would decrease the climate impact of heat energy by $81 \%$. With both these changes, the reduction would be $84 \%$ for the entire sector's climate impact. The changes can be supported by authorities and on the other hand low climate impact can be also good for marketing. In addition, we recommended to redo the investigation so that it observes the possible impact of replacement of peat and change to renewable energy electricity on the results. One shortcoming is related to the energy data, which does not cover $100 \%$ of the Finnish greenhouses, but is nevertheless the best available data for this purpose.

Because the climate impact was in 2017 only about half than in 2004, the communication by using these old results would have lea to misleading conclusions. The same effect can be for other products of food sector as well- and also for other consumption sectors. That is why we recommend to repeat the LCA-studies regularly.

Finally, there are still possibilities to continue the reduction of carbon footprint and development of renewable energy and regarding energy source decisions, which could be supported by the authorities by for example lowering energy taxes for renewable energy use.

\section{Acknowledgements}

This study was funded by Finnish Glasshouse Growers' Association and Natural Resources Institute Finland (Luke). Without their support conducting of this study would not have been possible.

\section{Highlights}

- Climate impact declined by $35-61 \%$

- Main reason increased use of renewable energy

\section{References}

1. Salo M, Savolainen H, Karhinen S, et al. (2020) Drivers of household consumption expenditure and carbon footprints in finland. Journal of Cleaner Production 289: 1256007.

2. Nijdam DS, Wilting HC, Goedkoop MJ, et al. (2005) Environmen- 
tal load from dutch private consumption-how much damage takes place abroad? Journal of Industrial Ecolology 9: 147-168.

3. Tukker A, Jansen B (2006) Environmental impacts of products: A detailed review of studies. Journal of Industrial Ecology 10: 159182.

4. Carlsson-Kanyama A, Gonzàlez A (2009) Potential contributions of food consumption patterns to climate change. Am J Clin Nutr 89: 1704S-1709S.

5. Garnett T (2011) Where are the best opportunities for reducing greenhouse gas emissions in the food system (including the food chain)? Food Policy 36: S23-S32.

6. Saarinen M, Kurppa S, Virtanen $Y$, et al. (2012) Life cycle assessment approach to the impact of home-made, ready-to-eat and school lunches on climate and eutrophication. Journal of Cleaner Production 28: 177-186.

7. Hallström E (2015) Sustainable nutrition. Opportunities, risks and uncertainties from environmental and health perspectives. Doctoral dissertation defence, Sweden.

8. Scherhaufer S, Moates G, Hartikainen H, et al. (2018) Environmental impacts of food waste in Europe. Waste Manag 77: 98113.

9. Willet W, Rockström J, Loken B (2019) Food in the Anthropocene: The EAT-Lancet Commission on healthy diets from sustainable food systems. Lancet 393: 447-492.

10. Katajajuuri J-M, Silvennoinen $\mathrm{K}$, Hartikainen $\mathrm{H}$, et al. (2014) Food waste in the Finnish food chain. Journal of Cleaner Production 73: 322-329.

11. Boulard T, Raeppel C, Brun R, et al. (2011) Environmental impact of greenhouse tomato production in France. Agronomy for Sustainable Development, Springer Verlag/EDP Sciences/INRA 31: 757-777.

12. Page G, Ridoutt B, Bellotti B (2012) Carbon and water footprint tradeoffs in fresh tomato production. Journal of Cleaner Production 32: 219-226.

13. Antón A, Montero Jl, Muñoz P, et al. (2005a) Identification of the main factors affecting the environmental impact of passive greenhouses. Acta Horticulturae 691: 489-494.

14. Ntinas GK, Neumair M, Tsadilas CD, et al. (2017) Carbon footprint and cumulative energy demand of greenhouse and openfield tomato cultivation systems under Southern and Central European climatic conditions. Journal of Cleaner Production 142 : 3617-3626.

15. Neira DP, Montiel MS, Cabeza MD et al. (2018) Energy use and carbon footprint of the tomato production in heated multi-tunnel greenhouses in almeria within an exporting agri-food system context. Sci Total Environ 628-629: 1627-1636.

16. Silvenius F (2013) Possibilities in sustainable development in Finnish greenhouse production. In: Futures for food, 6-7 June 2013. $15^{\text {th }}$ international futures conference, Turku, Finland.

17. Torrellas M, Antón A, Lopez JC, et al. (2012) LCA of a tomato crop in a multi-tunnel greenhouse in almeria. The International J Life Cycle Assess 17: 863-875.

18. Brodt SB, Kramer KJ, Kendall A, et al. (2013) Comparing environmental impacts of regional and national-scale food supply chains: A case study of processed tomatoes. Journal of Food Policy 42: 106-114.

19. Ruokatieto (2020) Tietohaarukka. Tilastotietoa elintarvikelasta.
20. Kaukoranta T, Särkkä LE, Jokinen K (2014) Energy efficiency of greenhouse cucumber production under LED and HPS lightning. International symposium on new technologies and management of greenhouses-greensys 2015.

21. Audsley E, Brander M, Chatterton J, et al. (2009) How low can we go? An assessment of greenhouse gas emissions from the UK food system and the scope to reduce them by 2050. WWF UK.

22. Pluimers JC, Bakker EJ, Challa H, et al. (2001) An environmental systems analysis of greenhouse horticulture in the Netherlands -the tomato case.

23. Theurl MC, Haberl H, Erb KH, et al. (2014) Contrasted greenhouse gas emissions from local versus long-range tomato production. Agronomy for Sustainable Development 34: 593-602.

24. Almeida J, Achten WMJ, Verbist B, et al. (2014) Carbon and water footprints and energy use of greenhouse tomato production in northern italy. Journal of Industrial Ecology 18: 898-908.

25. Dias GM, Ayer NW, Khosla S, et al. (2017) Life cycle perspectives on the sustainability of ontario greenhouse tomato production: Benchmarking and improvement opportunities. Journal of Cleaner Production 140: 831-839.

26. Shah SAR, Naqvi SAA, Anwar S (2020) Exploring the linkage among energy intensity, carbon emission and urbanization in pakistan: Fresh evidence from ecological modernization and environment transition theories. Environ Sci Pollut Res Int 27: 40907-40929.

27. Naqvi SAA, Shah SAR, Mehdi MA (2020) Revealing empirical association among ecological footprints, renewable energy consumption, real income, and financial development: A global perspective. Environ Sci Pollut Res 27: 42830-42849.

28. Torrellas M, Antón A, Montero Jl (2013) An environmental impact calculator for greenhouse production systems. J Environ Manage 118: 186-195.

29. Kaukoranta T, Näkkilä J, Särkkä LE, et al. (2014) Effects of lightning, semi-closed greenhouse, and split-root fertigation on energy use and $\mathrm{CO} 2$ emissions in high latitude cucumber growing. Agricultural and Food Science 23: 220-235.

30. Yrjänäinen H, Silvenius F, Kaukoranta T, et al. (2013) Climate Impact assessment of greenhouse products: Final report. MTT Raport 83: 43 .

31. PAS 2012 (2012) PAS 2050-1:2012 Assessment of life cycle greenhouse gas emissions of horticultural products. The British Standards institution.

32. Luke (2019) Horticultural Statistics.

33. Alakangas E, Hurskainen M, Laatikainen-Luntama J, et al. (2016) Properties of fuels used in Finland. VTT Technology 258: 229.

34. Yrjänäinen (2011) Carbon footprint of Electricity in Finland. Master of Science Thesis, Tampere University of Technology, Master's degree programme in Electrical Enginerring.

35. Yara International (2012) Carbon footprint. Reduction of the carbon footprint of fertilization.

36. IPCC guidelines for national greenhouse gas inventories (2006) $\mathrm{N} 2 \mathrm{O}$ emissions from managed soils, and $\mathrm{Co}_{2}$ emissions from lime and urea application.

37. AGA (2012) Hiilidioksidilannoitus. In: Finnish: Carbon dioxide fertilising.

38. Kool A, Blonk H (2011) An LCA of stone wool and coco substrate as growing media in the Netherlands. 
39. Seppälä J, Grönroos J, Koskela S, et al. (2010) Climate impacts of peat fuel utilization chains - a critical review of the Finnish and Swedish life cycle assessments. The Finnish Environment.

40. Silvan N, Silvan K, Väisänen S, et al. (2012) Excavation-drier method of energy-peat extraction reduces long-term climatic impact. Boreal Environment Research 17: 263-276.

41. Kirkinen J, Minkkinen K, Penttilä BT, et al. (2007) Greenhouse impact due to different peat fuel utilisation chains in Finland: $A$ life-cycle approach. Boreal Env Res 12: 211-223.

42. Kirkinen J, Hillebrand K, Savolainen I (2007) Climate impact of energy use of peat land: Land use scenario. VTT tiedotteita 2365: 58.

43. Pohjala M (2014) What are the climate impacts of different life cycles of energy and horticultural peat? Master's thesis, University of Helsinki.

44. Remes $L$ (2018) Use of plastics in greenhouse production. Finnish Glasshouse Growers' Association.

45. Boldrin A, Hartling KR, Maria Laugen L, et al. (2010) Environmental inventory modeling of the use of compost and peat in growth media preparation. Resources, Conservation and Recycling 54: 1250-1260.

46. EASEWASTE (2007) Life cycle assessment modeling of solid waste systems. EASEWASTE modeling software. Landfill data from 6/2007.

47. VTT (2017) LIPASTO - A calculation system for traffic exhaust emissions and energy consumption in Finland.

48. Solomon S, Qin D, Manning M (2017) Technical Summary In: Climate Change 2007: The Physical Science Basis. Contribution of Working Group I to the Fourth Assessment Report of the Intergovernmental Panel on Climate Change. Cambridge University Press, New York, 19-91.
49. Hendricks P (2012) Life cycle assessment of Greenhouse Tomato (Solanum lycopersinum L.) Production in Southwestern Ontario. Engineering.

50. Katajajuuri JM, Grönroos J, Mikkola A, et al. (2007) Environmental Impacts Of Finnish Greenhouse Cucumber Production Systems. In: Book of Proceedings, 5th International Conference LCA in Foods, 25 - 26 April 2007, Gothenburg, Sweden. The Swedish Institute for Food and Biotechnology, 133-137.

51. Antón A, Montero JI, Munoz P, et al. (2005b) LCA and tomato production in Mediterranean greenhouses. International Journal of Agricultural Resources, Governance and Ecology 4: 102-112.

52. Khoshnevisan B, Rafiee S, Omid M, et al. (2013) Environmental impact assessment of tomato and cucumber cultivation in greenhouses using life cycle assessment and adaptive neuro-fuzzy inference system. Journal of Cleaner Production 73: 183-192.

53. Payen S, Basset-Mens C, Perret S (2015) LCA of local and imported tomato: An energy and water trade-off. Journal of Cleaner Production 87: 139-148.

54. Zarei MJ, Kazemi N, Marzban A (2019) Life cycle environmental impacts of cucumber and tomato production in open-field and greenhouse. Journal of the Saudi Society of Agricultural Sciences 18: $249-255$.

55. Del Borghi A, Gallo M, Strazza C, et al. (2014) An evaluation of environmental sustainability in the food industry through life cycle assessment: The case study of tomato products supply chain. Journal of Cleaner Production 78: 121-130.

56. Jones CD, Fraisse CW, Ozores-Hampton M (2012) Quantification of greenhouse gas emissions from open field-grown florida tomato production. Agricultural Systems 113: 64-72.

DOI: $10.36959 / 745 / 408$

Copyright: (C) 2021 Silvenius F, et al. This is an open-access article distributed under the terms of the Creative Commons Attribution License, which permits unrestricted use, distribution, and reproduction in any medium, provided the original author and source are credited. 